\title{
Contemporary Management of Stable Coronary Artery Disease
}

\author{
Dario Tino Bertolone ${ }^{1,2} \cdot$ Emanuele Gallinoro ${ }^{1,3} \cdot$ Giuseppe Esposito $^{1,2} \cdot$ Pasquale Paolisso ${ }^{1,2}$. \\ Konstantinos Bermpeis ${ }^{1} \cdot$ Cristina De Colle $^{1,2}$. Davide Fabbricatore ${ }^{1,2} \cdot$ Niya Mileva $^{1}$. Chiara Valeriano ${ }^{1}$. \\ Daniel Munhoz ${ }^{1,2}$. Marta Belmonte ${ }^{1} \cdot$ Marc Vanderheyden $^{1}$. Jozef Bartunek ${ }^{1}$. Jeroen Sonck ${ }^{1,2}$. Eric Wyffels ${ }^{1}$. \\ Carlos Collet ${ }^{1} \cdot$ Costantino Mancusi $^{2} \cdot$ Carmine Morisco $^{2} \cdot$ Nicola De Luca $^{2} \cdot$ Bernard De Bruyne $^{1,4}$. \\ Emanuele Barbato ${ }^{1,2}$ (I)
}

Received: 9 October 2021 / Accepted: 30 November 2021 / Published online: 11 February 2022

(c) The Author(s) 2022

\begin{abstract}
Coronary artery disease (CAD) continues to be the leading cause of mortality and morbidity in developed countries. Assessment of pre-test probability (PTP) based on patient's characteristics, gender and symptoms, help to identify more accurate patient's clinical likelihood of coronary artery disease. Consequently, non-invasive imaging tests are performed more appropriately to rule in or rule out CAD rather than invasive coronary angiography (ICA). Coronary computed tomography angiography (CCTA) is the first-line non-invasive imaging technique in patients with suspected CAD and could be used to plan and guide coronary intervention. Invasive coronary angiography remains the gold-standard method for the identification and characterization of coronary artery stenosis. However, it is recommended in patients where the imaging tests are non-conclusive, and the clinical likelihood is very high, remembering that in clinical practice, approximately 30 to $70 \%$ of patients with symptoms and/or signs of ischemia, referred to coronary angiography, have non obstructive coronary artery disease (INOCA). In this contest, physiology and imaging-guided revascularization represent the cornerstone of contemporary management of chronic coronary syndromes (CCS) patients allowing us to focus specifically on ischemia-inducing stenoses. Finally, we also discuss contemporary medical therapeutic approach for secondary prevention. The aim of this review is to provide an updated diagnostic and therapeutic approach for the management of patients with stable coronary artery disease.
\end{abstract}

Keywords Coronary artery disease $\cdot$ Angina $\cdot$ Fractional flow reserve $\cdot$ Percutaneous coronary intervention $\cdot$ Chronic coronary syndrome $\cdot$ Coronary computed tomography angiography

\section{Introduction}

Coronary artery disease (CAD) continues to be the leading cause of mortality and morbidity in developed countries. This review aims to describe diagnostic pathways of stable CAD including non-invasive assessments with modern estimates of pre-test probability (PTP), contemporary indication

Emanuele Barbato

emanuele.barbato@olvz-aalst.be

Cardiovascular Center Aalst, OLV-Clinic, Aalst, Belgium

2 Department of Advanced Biomedical Sciences, University of Naples Federico II, Naples, Italy

3 Department of Translational Medical Sciences, University of Campania "Luigi Vanvitelli", Naples, Italy

4 Department of Cardiology, Lausanne University Hospital, Lausanne, Switzerland for invasive coronary angiography (ICA) and revascularization, suggestions for the implementation of guidelinesdirected medical therapy.

\section{Non-Invasive Assessment}

\subsection{Patients Selection: Pre-Test Probability (PTP) and Clinical Likelihood}

Assessment of the pre-test probability (PTP) is a fundamental step to safely and effectively refer patients to the appropriate non-invasive and invasive diagnostic pathway [1]. The latest European Society of Cardiology (ESC) guidelines on Chronic Coronary Syndromes (CCS) proposed to integrate the PTP with a wider concept of "clinical likelihood of CAD", considering that multiple 
cardiovascular risk factors can act as risk modifiers of the PTP estimate [2]. Specifically, in patients with suspected CAD, the new risk stratification allows reducing the need for non-invasive and invasive tests if the PTP is $<5 \%$, while for patients with an 'intermediate' probability of CAD (PTP ranges from 5 to $15 \%$ ) Guidelines suggest that patients should undergo further non-invasive evaluation [3]. In addition, patients should not be directly referred to invasive assessment unless clinical or non-invasive testing indicate a high likelihood of obstructive CAD [4].

\subsection{Coronary Computed Tomography Angiography (CCTA)}

In the last decades, coronary computed tomography angiography (CCTA) has emerged as a non-invasive alternative for the assessment of epicardial coronary artery disease. The current new generation CT scanners enable improved image quality with reduced contrast volume and radiation dosage [5]. The PROMISE trial demonstrated the incremental value of coronary CTA in patients with suspected CAD and highlighted the potential of CCTA to reduce the number of unnecessary invasive coronary angiographies (ICA) [6]. The SCOT-HEART showed that at a median follow-up of 5 years, CCTA, in addition to standard care in patients with stable chest pain, was associated with a significant reduction in cardiovascular death and non-fatal myocardial infarction than standard care alone, without resulting in a significantly higher rate of ICA or coronary revascularization [7]. Based on these and previous evidence, the recent recommendations on managing patients with chronic coronary syndrome proposed CCTA as a first-line diagnostic tool for people in whom stable angina cannot be excluded by clinical assessment alone [2].

Furthermore, beyond the anatomic evaluation, methods derived by CCTA that allow for the assessment of the functional significance of CAD have been introduced in the clinical field. Stress myocardial computed tomography perfusion (CTP) demonstrated similar performance to nuclear imaging and showed an additional diagnostic value to CCTA alone as compared to invasive fractional flow reserve (FFR) [8].

Fractional flow reserve derived from coronary CTA (FFRCT) technology is based on the application of computational fluid dynamics to 3D geometries extracted from coronary CTA data [9]. The FFRCT expanded the application of coronary CTA to include the functional component of epicardial coronary stenosis. Moreover, FFRCT showed good accuracy vs invasive FFR and an excellent cost-effectiveness leading to reduced number of ICA [10].

\subsection{Non-Invasive Functional Evaluation}

Non-invasive functional tests may be preferred in patients with intermediate-to-high PTP and clinical likelihood of obstructive CAD, in those with known CAD, and in those who are likely to undergo revascularization. Moreover, they are recommended when CCTA has provided uncertain or inclusive diagnostic information [2].

\subsubsection{Rest and Stress Echocardiography}

The 2D standard echocardiography allows the assessment of the left ventricular ejection fraction (LVEF) and the estimation of the regional myocardial contractility. LVEF is often normal in patients with CCS. A decreased LV function and/ or regional wall motion abnormalities might be suspected of CAD, mostly if the LV hypo-akinetic pattern follows the coronary arteries distribution territory [11].

Recent studies showed that the 2D speckle tracking echocardiography (2D-STE) could significantly improve the detection of regional wall motion abnormalities in patients with apparently normal LV function, identifying high-risk patients [12]. Some studies demonstrated a high prognostic value of 2D-STE in patients with known or suspected CAD [13]. Diastolic dysfunction and decreased left atrial strain have been reported to be an early sign of myocardial ischemia and could be indicative of microvascular dysfunction [14-16].

As pointed out above, in patients with moderate-to-high PTP for CAD, functional non-invasive tests are generally needed to evaluate the presence and the possible functional impact of CAD. In this setting, stress echocardiography (SE) could detect wall motion abnormalities, induced by exercise or pharmacological stressors, with sensitivity and specificity ranging between $72-85 \%$ and $77-95 \%$ [2, 17]. However, the presence of poor image quality and the low inter-observer reproducibility affects the diagnostic accuracy of this tool. In this setting, the contrast echocardiography can significantly improve diagnostic accuracy and SE daily use in clinical practice. Importantly, beyond the wall motion abnormalities, SE might assess coronary flow reserve (CFR), which may add further prognostic power. In a large prospective observational study of dipyridamole SE, including patients with known or suspected CAD, CFR on the left anterior descending artery was a strong and independent indicator of mortality, conferring additional prognostic value over wall motion analysis [18].

Echocardiography is also an important clinical tool for the exclusion of non-ischemic cardiac causes of chest pain (valvular heart diseases, pericarditis, and heart failure), conditions that can coexist with obstructive CAD. 


\subsubsection{SPECT and CMR}

Functional imaging tests also include myocardial perfusion scintigraphy by single-photon emission computed tomography (SPECT) or positron emission tomography (PET) and stress cardiac magnetic resonance (CMR). The main strengths of functional tests are the high accuracy in the detection of obstructive CAD [19] and location of ischemia, and a remarkable efficiency for risk-stratification of patients with CAD [20].

\section{Invasive Assessment}

\subsection{Invasive Coronary Angiography (ICA)}

Invasive coronary angiography is considered the gold-standard method for identification and characterization of coronary artery stenosis. Yet, ICA is limited by the evaluation of a 3D vascular structure as a two-dimensional imaging, and by the inability to accurately identify the hemodynamic significance of the intermediate coronary stenosis [21]. The invasive physiologic assessment has the aim to overcome these limitations, assessing the ischemic impact of the coronary stenoses [22].

\subsection{Physiology Guidance of Revascularization}

The purpose of revascularization in CCS patients is the improvement of angina symptoms, reducing the use of antianginal drugs, and possibly the improvement of prognosis, by reducing the risk of MACE and increasing exercise capacity and quality of life [2]. By specifically targeting the ischemia-inducing stenoses, physiology-guided revascularization represents the cornerstone of contemporary management of CCS patients.

\subsubsection{FFR-Guided PCI}

The best validated index to assess the hemodynamic significance of a coronary stenosis is the Fractional Flow Reserve (FFR) [22, 23]. Several RCTs evaluated the use of FFR for the functional assessment of lesion severity and guide revascularization. The DEFER trial demonstrated the safety and efficacy (15 years of follow-up) of deferral PCI in stenosis with FFR > 0.75 [24]. It has demonstrated that FFR-based assessment at the time of diagnostic coronary angiography in patients with CCS modifies the revascularization strategy from medical therapy to revascularization with PCI or CABG in $>40 \%$ of patients [25]. In patients with multivessel coronary artery disease undergoing PCI, the FAME trial showed that an FFR guided PCI was associated with a reduction in the composite endpoint of death, MI and repeat revascularization at 24 months compared to angiographyguided PCI alone and a reduction in resource used [26, 27]. In CCS patients, the FAME II trial demonstrated that in lesions with an FFR $<0.80$, FFR-guided PCI with medical therapy was associated with a three-fold decrease in the cumulative incidence of death, MI and urgent revascularization compared to optimal medical therapy alone [28]. The 3- and 5-years follow-up of the FAME II trials confirmed the advantages of FFR-guided PCI plus OMT vs OMT alone in terms of significantly lower rate of urgent revascularization, MI, and death $[29,30]$.

Since FFR evaluation requires maximal and stable hyperemia, non-hyperemic pressure ratio indexes (NHPR) have been recently introduced to overcome the need for adenosine. The instantaneous wave-free ratio (iFR), a resting index of functional stenosis severity, has been demonstrated to be non-inferior to FFR in guiding PCI in the two largest RCTs, the DEFINE-FLAIR and the iFR SWEDEHEART, highlighting comparable rates of MACE at 1-year follow-up[31, 32] (Table 1). Nevertheless, compared to FFR, iFR lacks long-term follow-up data.

\subsubsection{FFR-Guided CABG}

Traditionally, Coronary Artery Bypass Grafting (CABG) has been performed according to visual estimation of stenosis severity through ICA. The role of FFR-Guided CABG is still under evaluation. Clinical studies and retrospective registries showed that in patients undergoing $\mathrm{CABG}$, a preoperative FFR-guided strategy is associated with a lower number of graft anastomoses and a higher graft patency rate compared to an ICA-guided approach [33,34]. After 6 years of followup, FFR-guided CABG is associated with a lower rate of overall death and MI [35]. These results obtained in observational registries were not confirmed in the two available RCTs, FARGO and GRAFFITI, most likely as consequence of the small sample size and short follow-up available [36, 37]. Finally, The IMPAG prospective registry demonstrated a high patency rate $(97 \%)$ for grafts placed on coronary arteries with FFR less than 0.78 [38].

\subsubsection{Pullback Pressure Gradient (PPG)}

The hyperemic Pullback Pressure Gradient (PPG) index was developed to quantifies the spatial distribution of epicardial resistances and discriminates between focal and diffuse epicardial atherosclerosis (Fig. 1) [39, 40]. The higher the PPG index, the more focal the CAD, the lower the PPG index, the more diffuse CAD [41]. This novel index could help clinical decision making about revascularization strategy, since diffuse CAD are often management with OMT or referred to CABG, whereas focal lesions are treated by PCI. 
Table 1 RCTs using Physiological Assessment

\begin{tabular}{|c|c|c|c|c|c|c|}
\hline Study name & $\begin{array}{l}\text { Year of } \\
\text { publica- } \\
\text { tion }\end{array}$ & Study design & $\begin{array}{l}\text { Num- } \\
\text { ber of } \\
\text { patients }\end{array}$ & Groups & Primary endpoint & Conclusions \\
\hline DEFER & 2015 & RCT & 325 & $\begin{array}{l}\text { Deferral with FFR }>0.75 \\
\text { vs. performed PCI with } \\
\text { FFR }<0.75\end{array}$ & MI & $\begin{array}{l}\text { Safety and Efficacy of } \\
\text { deferral PCI in stenosis } \\
\text { with FFR }>0.75\end{array}$ \\
\hline FAME & 2009 & RCT & 1005 & $\begin{array}{l}\text { FFR-guided vs. angiogra- } \\
\text { phy-guided PCI }\end{array}$ & $\begin{array}{l}\text { Composite of death, MI } \\
\text { or revascularization }\end{array}$ & $\begin{array}{l}\text { FFR-guided PCI (FFR cut } \\
\text { off }<0.80 \text { ) was associated } \\
\text { with a reduction in PE } \\
\text { compared to angiogra- } \\
\text { phy-guided PCI }\end{array}$ \\
\hline FAME II & 2015 & RCT & 888 & $\begin{array}{l}\text { FFR-guided PCI + OMT } \\
\text { vs OMT alone }\end{array}$ & $\begin{array}{l}\text { Composite of death, MI, } \\
\text { revascularization }\end{array}$ & $\begin{array}{l}\text { FFR-guided PCI was } \\
\text { associated with a lower } \\
\text { occurrence of PE }(13.9 \% \\
\text { vs } 27 \% ; \mathrm{p}<0.001)\end{array}$ \\
\hline DEFINE-FLAIR & 2017 & RCT & 2492 & $\begin{array}{l}\text { FFR-guided vs. iFR- } \\
\text { guided PCI }\end{array}$ & $\begin{array}{l}\text { Composite of death, MI, } \\
\text { revascularization }\end{array}$ & $\begin{array}{l}\text { iFR-guided PCI is non- } \\
\text { inferior to FFR-guided } \\
\text { PCI (10.5\% vs. } 11.8 \% \text {; } \\
\text { p0.25) }\end{array}$ \\
\hline iFR SWEDEHEART & 2017 & RCT & 2037 & $\begin{array}{l}\text { FFR-guided vs. iFR- } \\
\text { guided PCI }\end{array}$ & $\begin{array}{l}\text { Composite of death, MI, } \\
\text { revascularization }\end{array}$ & $\begin{array}{l}\text { iFR-guided PCI is non- } \\
\text { inferior to FFR-guided } \\
\text { PCI ( } 8.4 \% \text { vs. } 8.7 \% \text {; } \\
\text { p0.93) }\end{array}$ \\
\hline
\end{tabular}

$F F R$ fractional flow reserve, $i F R$ instantaneous wave-free ratio, $O M T$ optimal medical therapy, $M I$ myocardial infarction, $P C I$ percutaneous coronary intervention, $P E$ primary endpoint.

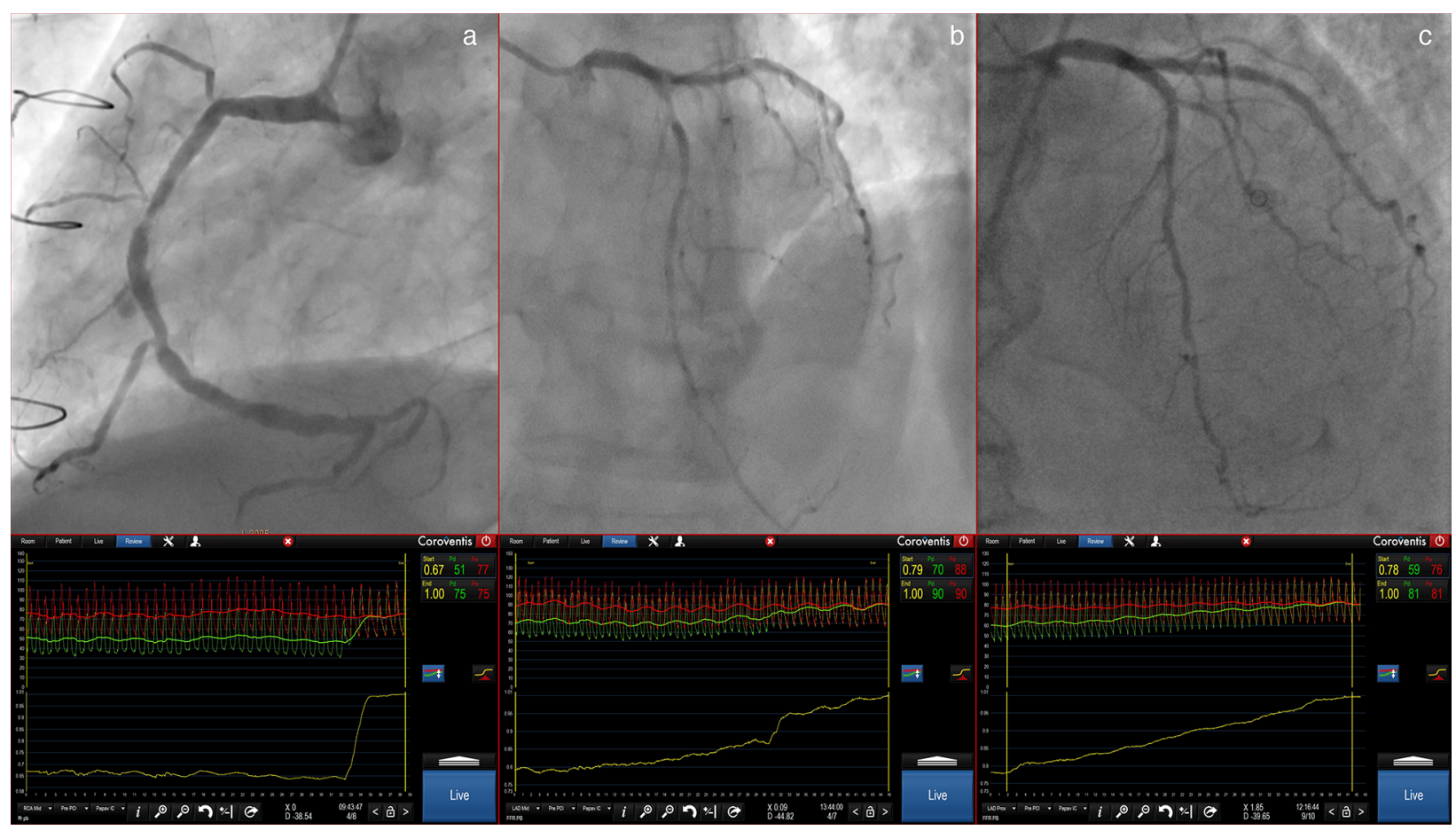

Fig. 1 Physiology guided discrimination of focal CAD. a Focal lesion in the proximal right coronary artery, with FFR 0.67 and a Pullback curve with a focal drop. PPG of 0.87 ; b combined lesion in the left descending artery (LAD) with FFR 0.79 and a Pullback curve show- ing diffuse disease with a proximal focal drop. PPG of 0.56; $\mathbf{c}$ diffuse coronary artery disease in an LAD with FFR 0.78 and a pullback curve without focal drops. PPG of 0.34. FFR fractional flow reserve, $P P G$ pullback pressure gradient. 


\subsection{Invasive Imaging Guided Revascularization}

Intravascular (IV) Imaging has significantly improved the PCI techniques and stent implantation [42]. The most used IV tools are optical coherence tomography (OCT) and intravascular ultrasound (IVUS). OCT has better spatial resolution but lower penetration than IVUS. These features make OCT more attractive for the definition of small details (e.g., thrombus, edge dissection, plaque rupture and erosion, calcium assessment) (Fig. 2), while IVUS is preferred in larger vessels, aorta-ostial lesions and in case higher penetration is needed (e.g., estimation of plaque burden, etc.). Given the larger burden of clinical evidence, IVUS is currently recommended to assess the severity of unprotected left main stenosis. In addition, both IVUS and OCT are recommended to guide and optimize stent implantation, especially in complex coronary lesions. Tables 2 and 3 are summarizing the main studies available [43-60].

\subsection{CCTA-Guided PCI}

CCTA can detect atherosclerosis at a very early stage and gives various information about the extent of coronary artery disease and especially the plaque characteristics [9]. A common problem in coronary revascularization, based only on conventional angiography, is the inaccurate evaluation of lesion length, which is associated with adverse events after stent implantation. The analysis of the CCTA provides us with metrics like the minimal lumen diameter (MLD), which can define nicely the lesion severity and reference vessel diameter (RVD) enabling to select the correct diameter of the stent. Furthermore, CCTA can characterize plaques qualitative and quantitively in a way that can guide revascularization. CCTA can identify high-risk plaques, especially non-calcified plaques (NCP) with low attenuation, plaques with spotty calcifications (SCPs) or plaques with positive remodeling with increased remodeling index (RI) have been identified as important features of plaque instability [61].

Furthermore, the combination of computed tomography and fractional flow reserve derived from CT angiography (FFRCT), assessing anatomy and physiology in one single study, can play an important role both in risk stratification and procedure planning [62]. A new tool, the FFRCT planner, is actually a new approach to predict the results of PCI in terms of post-PCI FFR. The FFRCT planner tool simulates luminal changes produced by PCI and calculates coronary pressures using the modified 'stented' geometry. In this way, the interventional cardiology could predict the benefit of a given PCI strategy [63]. A novel approach for CT-guided revascularization and the next step for a fully CTguided PCI, is the integration of CCTA using a 3D visualization software inside the Cath-lab. This adds three-dimension to conventional angiography and enables the visualization of atherosclerotic burden in the entire coronary tree (Fig. 3) [64]. CT-guided revascularization is an approach that steadily gains ground in the field of coronary interventions. CCTA

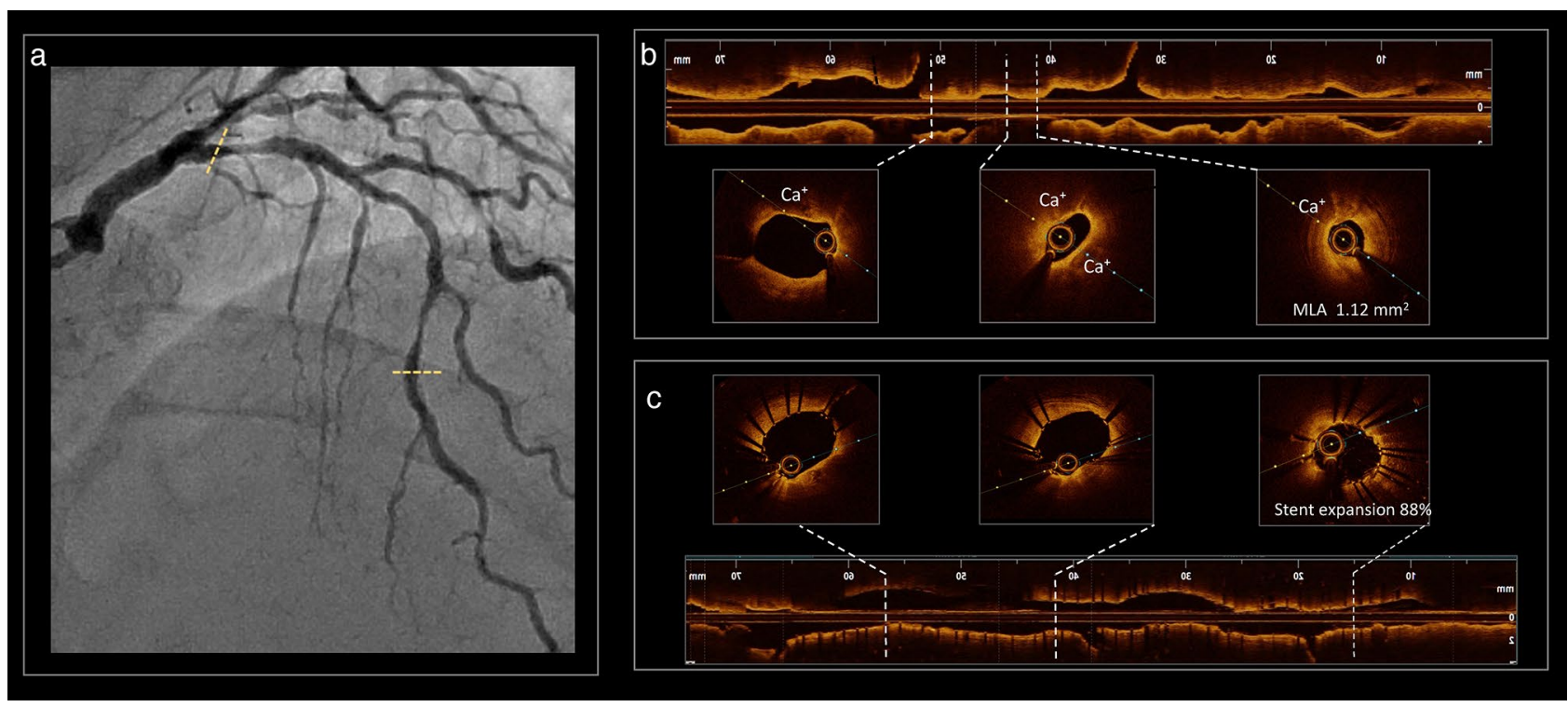

Fig. 2 Significant calcified lesion in proximal and middle left anterior descending artery. a Coronary angiography. Yellow dashed lines represent the proximal and distal edge of the implanted stents during the PCI. b OCT pre-PCI showing calcific lesion with significant stenosis and MLA of $1.12 \mathrm{~mm}^{2}$. $\mathbf{c}$ OCT post-PCI showing total stent length of $56 \mathrm{~mm}$ length and optimal stent expansions of $88 \%$. PCI percutaneous coronary intervention, $O C T$ optical coherence tomography, $M L A$ minimum lumen area. 
Table 2 Main studies available using OCT

\begin{tabular}{|c|c|c|c|c|c|c|}
\hline Study name & $\begin{array}{l}\text { Year of } \\
\text { publica- } \\
\text { tion }\end{array}$ & Study design & $\begin{array}{l}\text { Num- } \\
\text { ber of } \\
\text { patients }\end{array}$ & Groups & Primary endpoint & Conclusions \\
\hline COMPLETE OCT & 2020 & $\begin{array}{l}\text { Prospective observa- } \\
\text { tional }\end{array}$ & 93 & & $\begin{array}{l}\text { Prevalence TCFA in } \\
\text { obstructive and non- } \\
\text { obstructive lesions }\end{array}$ & $\begin{array}{l}\text { VP were more common } \\
\text { in obstructive lesions }\end{array}$ \\
\hline COMBINE OCT-FFR & 2016 & $\begin{array}{l}\text { Prospective observa- } \\
\text { tional }\end{array}$ & 550 & $\begin{array}{l}\text { Lesions with TCFA } \\
\text { vs. lesions without } \\
\text { TCFA }\end{array}$ & $\begin{array}{l}\text { Impact of plaque com- } \\
\text { positions on MACE }\end{array}$ & $\begin{array}{l}\text { TCFA were associated } \\
\text { with higher MACE }\end{array}$ \\
\hline CLIMA & 2020 & $\begin{array}{l}\text { Prospective observa- } \\
\text { tional }\end{array}$ & 1003 & & $\begin{array}{l}\text { Impact of plaque com- } \\
\text { positions on MACE }\end{array}$ & $\begin{array}{l}\text { VP were associated } \\
\text { with higher risk of MI }\end{array}$ \\
\hline CLI-OPCI II Study & 2015 & $\begin{array}{l}\text { Retrospective obser- } \\
\text { vational }\end{array}$ & 832 & & $\begin{array}{l}\text { Impact of post PCI- } \\
\text { OCT on MACE }\end{array}$ & $\begin{array}{l}\text { Suboptimal PCIs were } \\
\text { associated with higher } \\
\text { MACE }\end{array}$ \\
\hline ILUMIEN I & 2015 & $\begin{array}{l}\text { Prospective observa- } \\
\text { tional }\end{array}$ & 418 & & $\begin{array}{l}\text { Impact of OCT on } \\
\text { procedural decision } \\
\text { making }\end{array}$ & $\begin{array}{l}\text { In half of cases OCT } \\
\text { impact procedure } \\
\text { decision making (pre- } \\
\text { PCI) }\end{array}$ \\
\hline ILUMIEN II & 2015 & Observational & 940 & $\begin{array}{l}\text { OCT vs angiography- } \\
\text { guided PCI }\end{array}$ & $\begin{array}{l}\text { Post PCI stent expan- } \\
\text { sion }\end{array}$ & $\begin{array}{l}\text { Comparable degree of } \\
\text { stent expansion }\end{array}$ \\
\hline $\begin{array}{l}\text { ILUMIEN III OPTI- } \\
\text { MIZE PCI }\end{array}$ & 2016 & RCT & 450 & $\begin{array}{l}\text { OCT-vs-IVUS-vs } \\
\text { angiography-guided } \\
\text { PCI }\end{array}$ & Post PCI MSA & $\begin{array}{l}\text { (1) Similar MSA } \\
\text { between OCT and } \\
\text { IVUS, (2) inconclu- } \\
\text { sive for OCT superi- } \\
\text { ority on MACE }\end{array}$ \\
\hline
\end{tabular}

$V P$ vulnerable plaque, TCFA thin-cap-fibroatheroma, $L R P$ lipid-rich-plaque, $F P$ fibroatheroma, $P B$ plaque burden, $M S A$ minimum stent area, $M A C E$ major adverse cardiac events

Table 3 Main studies available using IVUS

\begin{tabular}{|c|c|c|c|c|c|c|}
\hline Study name & $\begin{array}{l}\text { Year of } \\
\text { publica- } \\
\text { tion }\end{array}$ & Study design & $\begin{array}{l}\text { Num- } \\
\text { ber of } \\
\text { patients }\end{array}$ & Groups & Primary endpoint & Conclusions \\
\hline PROSPECT & 2011 & $\begin{array}{l}\text { Prospective-observa- } \\
\text { tional }\end{array}$ & 697 & FP vs No FP & $\begin{array}{l}\text { Impact of FP plaque } \\
\text { on MACE in non- } \\
\text { culprit lesions }\end{array}$ & $\begin{array}{l}\text { TCFA was associated } \\
\text { with higher MACE }\end{array}$ \\
\hline PROSPECT ABS & 2020 & $\mathrm{RCT}$ & 182 & $\begin{array}{l}\text { PCI + medical therapy } \\
\text { vs. medical therapy } \\
\text { alone }\end{array}$ & $\begin{array}{l}\text { MLA after } 2 \text { years } \\
\text { (powered) TLF after } \\
2 \text { years (nonpow- } \\
\text { ered) }\end{array}$ & $\begin{array}{l}\text { PCI of mild lesions } \\
\text { with higher PB was } \\
\text { associated with } \\
\text { favorable outcome }\end{array}$ \\
\hline PROSPECT II & 2021 & RCT & 1643 & & $\begin{array}{l}\text { PB and LRP on } \\
\text { MACE }\end{array}$ & $\begin{array}{l}\text { LRP were associated } \\
\text { with MACE }\end{array}$ \\
\hline $\begin{array}{l}\text { ATHEROREMO- } \\
\text { IVUS }\end{array}$ & 2014 & $\begin{array}{l}\text { Prospective-observa- } \\
\text { tional }\end{array}$ & 581 & & $\begin{array}{l}\text { Association between } \\
\text { TCFA and MACE }\end{array}$ & $\begin{array}{l}\text { TCFA predict future } \\
\text { MACE }\end{array}$ \\
\hline PREDICTION & 2012 & $\begin{array}{l}\text { Prospective-observa- } \\
\text { tional }\end{array}$ & 506 & $\begin{array}{l}\text { Plaque characteristics } \\
\text { after PCI in ACS }\end{array}$ & $\begin{array}{l}\text { Increasing in plaque } \\
\text { area }\end{array}$ & $\begin{array}{l}\text { High PB and low } \\
\text { ESS predict plaque } \\
\text { progression }\end{array}$ \\
\hline LITRO & 2011 & $\begin{array}{l}\text { Prospective-observa- } \\
\text { tional }\end{array}$ & 354 & $\begin{array}{l}\text { LMCA MLA }<6 \mathrm{~mm}^{2} \\
\text { vs MLA }>6 \mathrm{~mm}^{2}\end{array}$ & $\begin{array}{l}\text { MLA } \geq 6 \mathrm{~mm}^{2} \text { as } \\
\text { threshold for LMCA }\end{array}$ & $\begin{array}{c}\text { MLA } \geq 6 \mathrm{~mm}^{2} \text { was a } \\
\text { safe value for PCI } \\
\text { deferring in LM }\end{array}$ \\
\hline ULTIMATE TRIAL & 2021 & RCT & 1448 & $\begin{array}{l}\text { IVUS vs angiography- } \\
\text { guided DES }\end{array}$ & TVF at 3 years & $\begin{array}{l}\text { IVUS-guided was } \\
\text { associated with a } \\
\text { lower rates TVF at } \\
\text { 3-years FU }\end{array}$ \\
\hline
\end{tabular}

TCFA-thin cap fibroatheroma. LRP-lipid rich plaque. FP-fibroatheroma. PB-plaque burden. MLA-minimum lumen area. MSA-minimum stent area. MACE-major adverse cardiac events. IC-intracoronary imaging. EES-endothelial shear stress. TLF-target lesion failure. TVF-target vessel failure. 


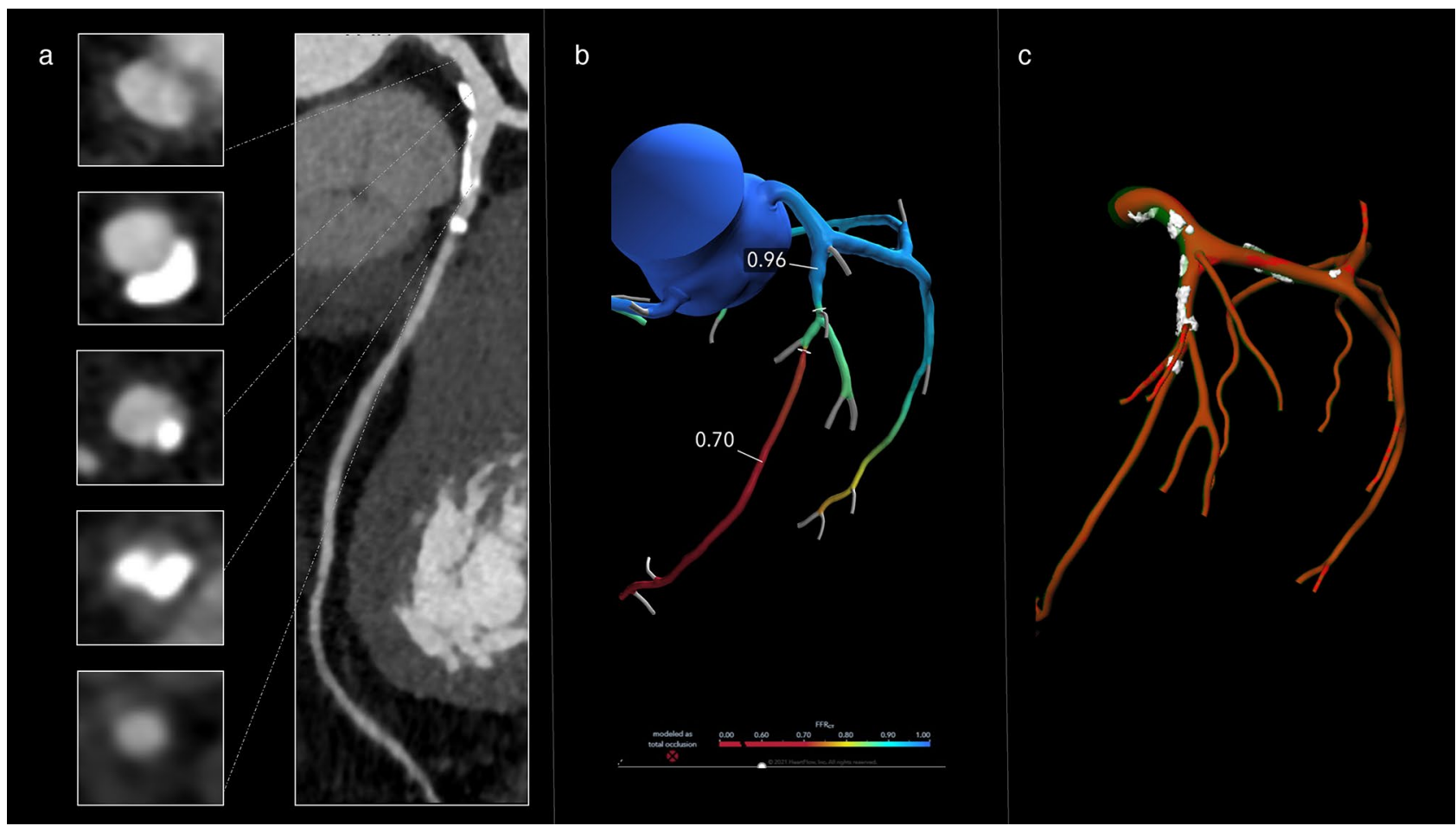

Fig. 3 Left anterior descending coronary artery with calcified lesion and significant stenosis in the proximal segment. a Coronary computed tomography angiography-curved multiplanar reconstruction

can be used to improve patient selection for PCI, to plan and guide coronary interventions [65].

\section{Ischemia Without Obstructive Epicardial Coronary Artery Disease (INOCA)}

Depending on the clinical series, approximately 30 to $70 \%$ of patients with angina and/or signs of ischemia referred to coronary angiography have non obstructive coronary artery disease [66]. INOCA is diagnosed with signs or symptoms of ischemia but in the absence of coronary artery stenosis $>$ $50 \%$ DS or with an FFR $<0.80$ (or iFR < 0.89) [67]. These patients deserve attention since INOCA has been associated with a worse clinical outcome [68].

In the ESC guidelines on CCS(2), the first line recommended testing for angina is non-invasive. In patients with no obstructive CAD on their CCTA and/or no regional reversible ischemia on functional testing, INOCA should be considered, and further non-invasive and invasive testing should be performed [67]. Non-invasive diagnosis of INOCA relies on interrogation of coronary vasomotor function by measuring regional and global myocardial blood flow at rest and during stress, microvascular resistance, and coronary flow reserve (CFR) calculated as the ratio of hyperemic to rest absolute myocardial blood flow. Positron emitted tomography (PET), and cross-sectional views. b FFRCT patient-specific model with distal value of $\mathrm{FFRCT}<0.70$. c 3D reconstruction model with visualization of plaque components.

Cardiac Magnetic Resonance (CMR) and Dynamic myocardial perfusion CT are mainly limited by the reduced availability and long post-processing [69]. Doppler echocardiography in the left anterior descending artery is operator-dependent and limited by the poor acoustic window. Nevertheless, perfusion assessment lacks the sensitivity to diagnose the relative contributions of epicardial and microvascular disease to myocardial blood flow reduction. In addition, some patients with a propensity to vasospastic chest pain syndromes may have normal findings from pharmacological and exercise stress testing and acetylcholine for provocative tests can be administered only during invasive testing [69]. Thus, a full diagnostic assessment for INOCA currently requires invasive angiography. Table 4 displays the invasive diagnostic workup for INOCA patients [70-74]. A diagnostic flowchart for non-invasive and invasive assessment is illustrated in Fig. 4. A similar algorithm for the diagnosis of CAD in hypertensive patients was previously proposed by the Italian Society of Hypertension [75]. Compared to the latter, in which the decision-making was based to the organ damage, we emphasize more the role of CCTA as first-line diagnostic approach and physiological assessment of stenosis-induced ischemia. 
Table 4 Invasive diagnostic workup three main endotypes of INOCA

\begin{tabular}{ll}
\hline Vasospastic angina (VSA) & FFR $>0.80 /$ iFR $>0.89$ \\
& CFR $\geq 2$ \\
& IMR $<25 / \mathrm{HMR}<1.9$ \\
& VRT $\rightarrow$ positive \\
& FFR $>0.80 /$ iFR $>0.89$ \\
Microvascular angina (MVA) & IFR $<2$ \\
& IMR $\geq 25 / \mathrm{HMR} \geq 1.9$ \\
Combined VSA and MVA & FFR $>0.80 /$ iFR $>0.89$ \\
& CFR $<2$ \\
& IMR $\geq 25 / \mathrm{HMR} \geq 1.9$ \\
& VRT $\rightarrow$ positive
\end{tabular}

$F F R$ fractional flow reserve, $C F R$ coronary flow reserve, $I M R$ index of microcirculatory resistance, $V R T$ vasoreactivity test

\section{Targets of Medical Therapy for Secondary Prevention}

\subsection{Lipid-Lowering Drugs}

The "low-density lipoprotein (LDL) hypothesis", i.e. the reduction of the LDL translates in a lower cardiovascular (CV) risk, has been widely accepted. Baigent et al. in a landmark metanalysis evaluating more than 90,000 patients by 14 trials with statins, observed that a reduction of $1 \mathrm{mmol}$ per liter $(38.7 \mathrm{mg}$ per deciliter) in LDL cholesterol levels carried a consistent $23 \%$ reduction in the risk of major coronary events over 5 years [76]. In consideration of the so-called "Residual Cardiovascular Risk", larger clinical trials have led to focus on the extreme reduction of LDL, regardless of the drug used to reach the goal [77].

The IMPROVE-IT trial with the Ezetimibe, the FOURIER and ODISSEY trials with the proprotein convertase subtilisin/kexin type 9 (PCSK9) monoclonal antibody therapies Evolocumab and Alirocumab, have shown an outstanding event-rate reduction directly related to the extreme reduction of LDL in patients with both chronic atherosclerotic cardiovascular disease and recent acute coronary syndrome $[78,79]$. Thus, ezetimibe and PCSK9 inhibitors nowadays offer additive and alternative options wherever the statin therapy tolerance is reduced by side effects, or the magnitude of LDL lowering is below the recommended targets [80, 81]. Remarkably, besides the hard clinical outcomes above described, Atorvastatin, Rosuvastatin and Evolocumab have also demonstrated reducing the progression of atherosclerosis in central and peripheral vessels [82-84]. In the light of the above, the LDL hypothesis has been rapidly relocated in the modern axiom of cardiology "the lower LDL, the better CV-risk profile" in such a way that the most

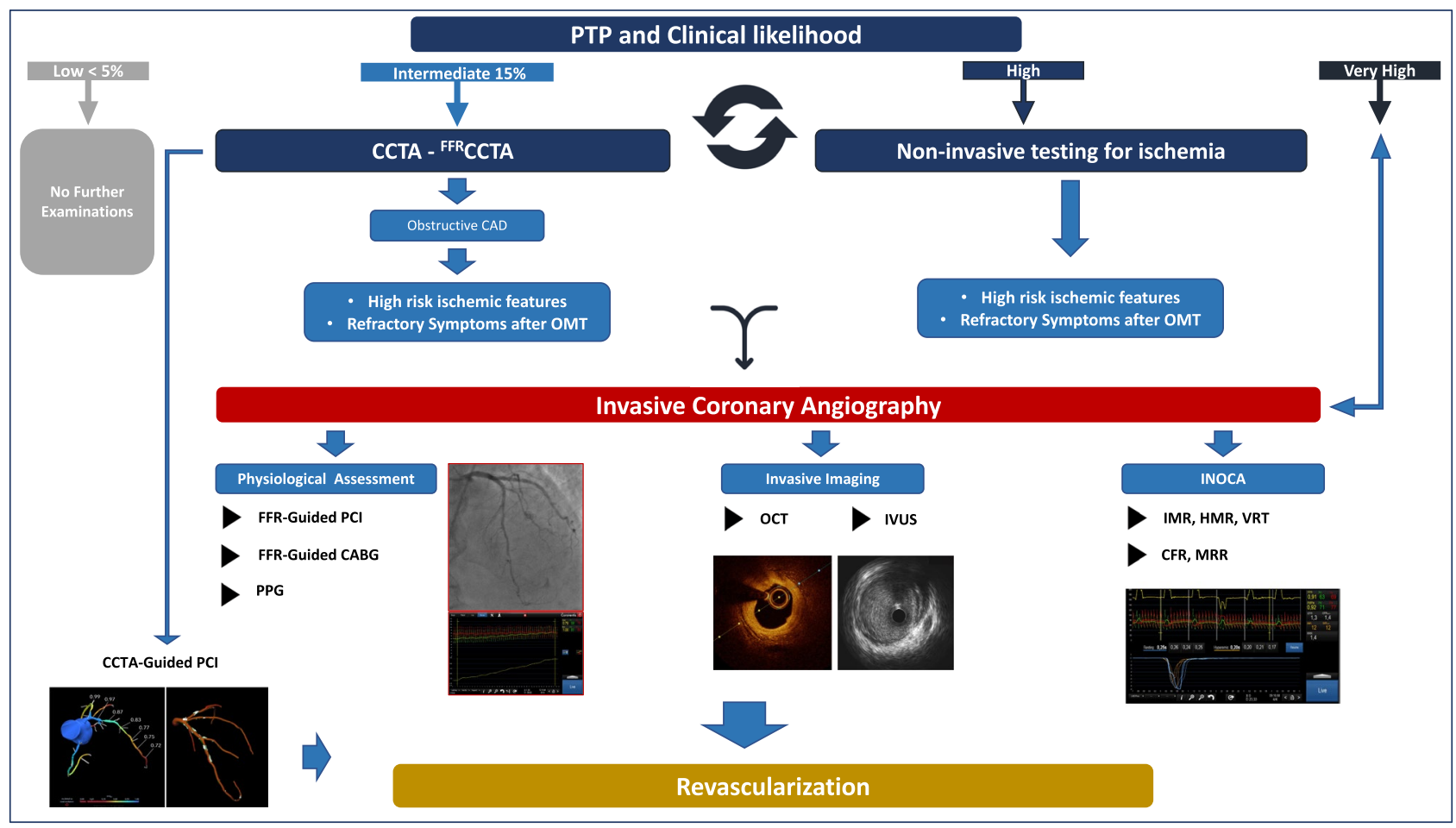

Fig. 4 Diagnostic flowchart for non-invasive and invasive assessment. CCTA coronary computed tomography angiography, FFR fractional flow reserve, $O M T$ optimal medical therapy, $P P G$ pullback pressure gradient, $O C T$ optical coherence tomography, IVUS intravascular ultrasound. 
recent European guidelines for the management of dyslipidemias suggest extreme targets of LDL (down to less than $40 \mathrm{mg} / \mathrm{dL}$ ) [81].

\subsection{Blood Pressure Treatment Targets}

Arterial Hypertension is the major preventable cardiovascular risk factor, strictly linked with CAD. Although the most recent ESC/ESH Guidelines define arterial hypertension as office $\mathrm{BP}$ values $\geq 140 / 90 \mathrm{mmHg}$, even suggest a more vigorous BP targets in hypertensive patients with CAD. Since an increased $\mathrm{BP} \geq 140 / 90 \mathrm{mmHg}$ as well as a $\mathrm{BP}<120 / 70$ $\mathrm{mmHg}$ are associated with unfavorable outcomes in these patients, a target BP of roughly $130 / 80 \mathrm{mmHg}$ can be recommended [85]. Furthermore in hypertensive patients with CAD and history of MI, beta-blockers and RAS- blockers are recommended.

\subsection{Ticagrelor 60 mg: Long-Term Secondary Prevention of Cardiovascular Events}

Aspirin is the cornerstone for the secondary prevention of acute coronary events [86]. The addition of a second antiplatelet agent, namely a P2Y12-receptor inhibitor, to aspirin further inhibits the extent of platelet aggregation and is generally indicated for limited period of times (1 year or less) after coronary stenting or an acute coronary syndrome (ACS). However, the reduction in the risk of ischemic events obtained with antiplatelet agents is usually counterbalanced by an increase in bleeding complications [87-89]. Long-term dual antiplatelet therapy (DAPT) for more than 1 year should therefore be considered for patients with an increased risk of ischemic events and without high bleeding risk [2]. Prolongation of DAPT with clopidogrel or prasugrel after 12 months of PCI with DES reduced the incidence of ischemic events and stent thrombosis, but without a mortality benefit and at the expense of increased bleeding [90]. The PEGASUS-TIMI 54 trial evaluated a strategy of long-term DAPT with ticagrelor $60 \mathrm{mg}$ b.i.d. or $90 \mathrm{mg}$ bid among 21,162 high-risk patients with a prior MI and without high bleeding risk. The study showed a significant reduction in the primary endpoint of cardiovascular death, MI, or stroke, with both ticagrelor dosages compared to placebo on top of aspirin therapy. However, the lower ticagrelor dose of $60 \mathrm{mg}$ appeared to be better tolerated, such that it preserved the efficacy in ischemic events without an excess in major bleeding complications as the 90 mg dose [91]. More recently, the THEMIS trial confirmed the ischemic benefit of long-term DAPT with ticagrelor $90 \mathrm{mg}$ versus aspirin alone among patients with stable CAD and diabetes, although the overall reduction in cardiovascular death, MI, or stroke was modest ( $7.7 \%$ vs $8.5 \%$ ) and burdened by a significant increase in the risk of intracranial hemorrhage [92]. Of note, the observed benefit of long-term ticagrelor was more evident in the subgroup of patients with a prior PCI. Conversely, a subgroup analysis of PEGASUS-TIMI 54 showed that the risk of MACE, cardiovascular and all-cause death was higher in patients with no history of PCI, due to their higher baseline risk [93], which suggests the importance of spontaneous, non-stent-related, atherothrombotic events in long-term clinical outcomes of patients with prior MI.

\subsection{Rivaroxaban for Secondary Cardiovascular Prevention in CAD patients}

After the advent of direct oral anticoagulants (DOAC), their use at lower dosages has been investigated in the context of ACS on top of antiplatelet therapy [94]. The ATLAS ACS 2 TIMI 51 trial tested two low-dose Rivaroxaban $(5 \mathrm{mg}$ and $2.5 \mathrm{mg}$, twice daily) and showed a reduction in the risk of MACE along with a survival benefit in the lower dose group [95]. A metanalysis of aggregate outcomes from 6 trials suggested that the benefit of DOACs in ACS patients may be enhanced in those with STEMI than NSTEMI [96].

The COMPASS trial compared three antithrombotic regimens (aspirin alone, Rivaroxaban $5 \mathrm{mg}$ twice daily and the combination of aspirin-plus-rivaroxaban $2.5 \mathrm{mg}$ twice daily) in patients with stable ischemic coronary or peripheral arterial disease (PAD) [97]. The rate of the primary endpoint of cardiovascular death, MI, or stroke was significantly reduced with combination therapy, with the largest clinical benefit observed in high-risk subgroups (multi-vessel peripheral disease, impaired renal function, heart failure, diabetes mellitus, or a combination of these risk characteristics) [98]. Major bleeding events were higher in the rivaroxaban groups than in the aspirin monotherapy group, but no significant between-group differences were observed in the rate of fatal bleeding, intracranial bleeding, or symptomatic bleeding into a critical organ [97].

Recent data suggest strong benefit in terms of cardiovascular events reduction with the intensification of antithrombotic therapy in high risk patients. Regardless of the lack of evidence between low-dose P2Y12-inhibitors and NOACs, the final choice should be guided by the patient's risk profile. Briefly, in patients with PEGASUS-like profile (i.e. highrisk with "recent" acute event and previous complex PCI) a long-term strategy with low-dose P2Y12 inhibitors should preferred, whereas in COMPASS-like patients (i.e. high risk patients with documented atherosclerotic vascular disease) NOACs therapy should be selected.

\section{Conclusion}

The optimal management of CCS patients with suspected or established CAD begins with the assessment of the best and more accurate PTP model in order to stratify the 
clinical likelihood of CAD. Non-invasive functional tests may be preferred in patients with intermediate-high PTP and in those who are likely to undergo revascularization. In this setting, the role of CCTA that combines anatomic and functional evaluation is of paramount importance both for the diagnostic capacity and for the ability to contribute to the planning of PCI or CABG, particularly in patients with multi-vessel CAD. The purpose of revascularization has to be an enhancement of angina symptoms and an improvement of prognosis. In this contest, physiology and imaging guidance of revascularization is the cornerstone of contemporary management of CCS patients. Regarding best secondary prevention, the objective is to obtain the lowest level of LDL with cholesterol-lowering medications, to reach the recommended BP values and prevent further ischemic events avoiding high risk of bleeding with low dose of P2Y12 inhibitors or NOACs.

\section{Declarations}

Funding and conflict of interest Dario Tino Bertolone, Pasquale Paolisso, Giuseppe Esposito, Davide Fabbricatore, Daniel Munhoz and Jeroen Sonck received a grant from the CardioPaTh PhD Program. Dr. Collet reports receiving research grants from Biosensor, Coroventis Research, GE Healthcare, Medis Medical Imaging, Pie Medical Imaging, Cathworks, Boston Scientific, Siemens, HeartFlow Inc. and Abbott Vascular; and consultancy fees from Heart Flow Inc, Opsens, Pie Medical Imaging, Abbott Vascular and Philips Volcano. Dr. De Bruyne has a consulting relationship with Boston Scientific, Abbott Vascular, CathWorks, Siemens, and Coroventis Research; receives research grants from Abbott Vascular, Coroventis Research, Cathworks, Boston Scientific; and holds minor equities in Philips-Volcano, Siemens, GE Healthcare, Edwards Life Sciences, HeartFlow, Opsens, and Celiad. Dr. Barbato declares speaker's fees from Abbott Vascular, Boston Scientific and GE.

Availability of data and material Findings were gathered from the published articles in the literature

Code availability Not applicable.

Author contributions DTB, EG, PP and GE wrote the first draft of the manuscript. DTB, EG, PP,CDC, NM, GE, KB,CV and DF performed the literature search. EB, MV, JS, JB, BDB, E.W, CC, CM, CM and NDL corrected and approved the revisions and final version of the manuscript and EB critically revised the work.

Research involving human participants and/or animals Not applicable.

Ethical approval Not applicable.

Informed consent Not applicable.

Open Access This article is licensed under a Creative Commons Attribution-NonCommercial 4.0 International License, which permits any non-commercial use, sharing, adaptation, distribution and reproduction in any medium or format, as long as you give appropriate credit to the original author(s) and the source, provide a link to the Creative Commons licence, and indicate if changes were made. The images or other third party material in this article are included in the article's Creative
Commons licence, unless indicated otherwise in a credit line to the material. If material is not included in the article's Creative Commons licence and your intended use is not permitted by statutory regulation or exceeds the permitted use, you will need to obtain permission directly from the copyright holder. To view a copy of this licence, visit http://creativecommons.org/licenses/by-nc/4.0/.

\section{References}

1. Gibbons RJ, Miller TD. Declining accuracy of the traditional diamond-forrester estimates of pretest probability of coronary artery disease: time for new methods. JAMA Intern Med. 2021;181:579-80.

2. Knuuti J, Wijns W, Saraste A, et al. 2019 ESC guidelines for the diagnosis and management of chronic coronary syndromes. Eur Heart J. 2020;41:407-77.

3. Di Carli MF, Gupta A. Estimating pre-test probability of coronary artery disease: battle of the scores in an evolving CAD landscape. JACC Cardiovasc Imaging. 2019;12:1401-4.

4. Winther S, Schmidt SE, Rasmussen LD, et al. Validation of the European Society of Cardiology pre-test probability model for obstructive coronary artery disease. Eur Heart J. 2021;42:1401-11.

5. Arbab-Zadeh A, Hoe J. Quantification of coronary arterial stenoses by multidetector CT angiography in comparison with conventional angiography methods, caveats, and implications. JACC Cardiovasc Imaging. 2011;4:191-202.

6. Douglas PS, Hoffmann U, Patel MR, et al. Outcomes of anatomical versus functional testing for coronary artery disease. N Engl J Med. 2015;372:1291-300.

7. CT coronary angiography in patients with suspected angina due to coronary heart disease (SCOT-HEART): an open-label, parallelgroup, multicentre trial. Lancet 2015;385:2383-91.

8. Ko BS, Cameron JD, Meredith IT, et al. Computed tomography stress myocardial perfusion imaging in patients considered for revascularization: a comparison with fractional flow reserve. Eur Heart J. 2012;33:67-77.

9. Taylor CA, Fonte TA, Min JK. Computational fluid dynamics applied to cardiac computed tomography for noninvasive quantification of fractional flow reserve: scientific basis. J Am Coll Cardiol. 2013;61:2233-41.

10. Douglas PS, Pontone G, Hlatky MA, et al. Clinical outcomes of fractional flow reserve by computed tomographic angiographyguided diagnostic strategies vs. usual care in patients with suspected coronary artery disease: the prospective longitudinal trial of FFR(CT): outcome and resource impacts study. Eur Heart J. 2015;36:3359-67.

11. Cerqueira MD, Weissman NJ, Dilsizian V, et al. Standardized myocardial segmentation and nomenclature for tomographic imaging of the heart. A statement for healthcare professionals from the Cardiac Imaging Committee of the Council on Clinical Cardiology of the American Heart Association. Circulation. 2002;105:539-42.

12. Biering-Sørensen T, Hoffmann S, Mogelvang R, et al. Myocardial strain analysis by 2-dimensional speckle tracking echocardiography improves diagnostics of coronary artery stenosis in stable angina pectoris. Circ Cardiovasc Imaging. 2014;7:58-65.

13. Munk K, Andersen NH, Terkelsen CJ, et al. Global left ventricular longitudinal systolic strain for early risk assessment in patients with acute myocardial infarction treated with primary percutaneous intervention. J Am Soc Echocardiogr. 2012;25:644-51.

14. Nagueh SF, Smiseth OA, Appleton CP, et al. Recommendations for the evaluation of left ventricular diastolic function by 
echocardiography: an update from the American Society of Echocardiography and the European Association of Cardiovascular Imaging. Eur Heart J Cardiovasc Imaging. 2016;17:1321-60.

15. Keulards DCJ, Bouwmeester S, de Vos AMJ, et al. High microvascular resistance and reduced left atrial strain in patients with coronary microvascular dysfunction: the micro-strain study. Int $\mathrm{J}$ Cardiol. 2021;333:21-8.

16. Gallinoro E, Paolisso P, Candreva A, et al. Microvascular dysfunction in patients with type II diabetes mellitus: invasive assessment of absolute coronary blood flow and microvascular resistance reserve. Front Cardiovasc Med. 2021;8:765071.

17. Heijenbrok-Kal MH, Fleischmann KE, Hunink MG. Stress echocardiography, stress single-photon-emission computed tomography and electron beam computed tomography for the assessment of coronary artery disease: a meta-analysis of diagnostic performance. Am Heart J. 2007;154:415-23.

18. Cortigiani L, Rigo F, Gherardi S, et al. Coronary flow reserve during dipyridamole stress echocardiography predicts mortality. JACC Cardiovasc Imaging. 2012;5:1079-85.

19. Knuuti J, Ballo H, Juarez-Orozco LE, et al. The performance of non-invasive tests to rule-in and rule-out significant coronary artery stenosis in patients with stable angina: a metaanalysis focused on post-test disease probability. Eur Heart J. 2018;39:3322-30.

20. Shaw LJ, Berman DS, Picard MH, et al. Comparative definitions for moderate-severe ischemia in stress nuclear, echocardiography, and magnetic resonance imaging. JACC Cardiovasc Imaging. 2014;7:593-604

21. Tonino PA, Fearon WF, De Bruyne B, et al. Angiographic versus functional severity of coronary artery stenoses in the FAME study fractional flow reserve versus angiography in multivessel evaluation. J Am Coll Cardiol. 2010;55:2816-21.

22. Pijls NH, De Bruyne B, Peels K, et al. Measurement of fractional flow reserve to assess the functional severity of coronary-artery stenoses. N Engl J Med. 1996;334:1703-8.

23. De Bruyne B, Fearon WF, Pijls NH, et al. Fractional flow reserveguided PCI for stable coronary artery disease. N Engl J Med. 2014;371:1208-17.

24. Zimmermann FM, Ferrara A, Johnson NP, et al. Deferral vs performance of percutaneous coronary intervention of functionally non-significant coronary stenosis: 15 -year follow-up of the DEFER trial. Eur Heart J. 2015;36:3182-8.

25. Curzen N, Rana O, Nicholas Z, et al. Does routine pressure wire assessment influence management strategy at coronary angiography for diagnosis of chest pain?: the RIPCORD study. Circ Cardiovasc Interv. 2014;7:248-55.

26. Tonino PA, De Bruyne B, Pijls NH, et al. Fractional flow reserve versus angiography for guiding percutaneous coronary intervention. N Engl J Med. 2009;360:213-24.

27. Pijls NH, Fearon WF, Tonino PA, et al. Fractional flow reserve versus angiography for guiding percutaneous coronary intervention in patients with multivessel coronary artery disease:2-year follow-up of the FAME (Fractional Flow Reserve Versus Angiography for Multivessel Evaluation) study. J Am Coll Cardiol. 2010;56:177-84.

28. De Bruyne B, Pijls NH, Kalesan B, et al. Fractional flow reserveguided PCI versus medical therapy in stable coronary disease. $\mathrm{N}$ Engl J Med. 2012;367:991-1001.

29. Fearon WF, Nishi T, De Bruyne B, et al. Clinical outcomes and cost-effectiveness of fractional flow reserve-guided percutaneous coronary intervention in patients with stable coronary artery disease: three-year follow-up of the FAME 2 trial (fractional flow reserve versus angiography for multivessel evaluation). Circulation. 2018;137:480-7.
30. van Nunen LX, Zimmermann FM, Tonino PA, et al. Fractional flow reserve versus angiography for guidance of PCI in patients with multivessel coronary artery disease (FAME): 5-year followup of a randomised controlled trial. Lancet. 2015;386:1853-60.

31. Davies JE, Sen S, Dehbi HM, et al. Use of the instantaneous wave-free ratio or fractional flow reserve in PCI. N Engl J Med. 2017;376:1824-34.

32. Götberg M, Christiansen EH, Gudmundsdottir IJ, et al. Instantaneous wave-free ratio versus fractional flow reserve to guide PCI. N Engl J Med. 2017;376:1813-23.

33. Botman CJ, Schonberger J, Koolen S, et al. Does stenosis severity of native vessels influence bypass graft patency? A prospective fractional flow reserve-guided study. Ann Thorac Surg. 2007;83:2093-7.

34. Toth G, De Bruyne B, Casselman F, et al. Fractional flow reserveguided versus angiography-guided coronary artery bypass graft surgery. Circulation. 2013;128:1405-11.

35. Fournier S, Toth GG, De Bruyne B, et al. Six-year follow-up of fractional flow reserve-guided versus angiography-guided coronary artery bypass graft surgery. Circ Cardiovasc Interv. 2018;11:e006368.

36. Thuesen AL, Riber LP, Veien KT, et al. Fractional flow reserve versus angiographically-guided coronary artery bypass grafting. J Am Coll Cardiol. 2018;72:2732-43.

37. Toth GG, De Bruyne B, Kala P, et al. Graft patency after FFRguided versus angiography-guided coronary artery bypass grafting: the GRAFFITI trial. EuroIntervention. 2019;15:e999-1005.

38. Glineur D, Grau JB, Etienne PY, et al. Impact of preoperative fractional flow reserve on arterial bypass graft anastomotic function: the IMPAG trial. Eur Heart J. 2019;40:2421-8.

39. Candreva A, Mizukami T, Sonck J et al. Hyperemic hemodynamic characteristics of serial coronary lesions assessed by pullback pressure gradients. Catheter Cardiovasc Interv. 2021.

40. Mizukami T, Sonck J, Gallinoro E, et al. Duration of hyperemia with intracoronary administration of papaverine. J Am Heart Assoc. 2021;10:e018562.

41. Collet C, Sonck J, Vandeloo B, et al. Measurement of hyperemic pullback pressure gradients to characterize patterns of coronary atherosclerosis. J Am Coll Cardiol. 2019;74:1772-84.

42. Koskinas KC, Ughi GJ, Windecker S, Tearney GJ, Räber L. Intracoronary imaging of coronary atherosclerosis: validation for diagnosis, prognosis and treatment. Eur Heart J. 2016;37:524-35a-c.

43. Prati F, Guagliumi G, Mintz GS, et al. Expert review document part 2: methodology, terminology and clinical applications of optical coherence tomography for the assessment of interventional procedures. Eur Heart J. 2012;33:2513-20.

44. Neumann FJ, Sousa-Uva M, Ahlsson A, et al. 2018 ESC/ EACTS Guidelines on myocardial revascularization. Eur Heart J. 2019;40:87-165.

45. Radu MD, Räber L, Heo J, et al. Natural history of optical coherence tomography-detected non-flow-limiting edge dissections following drug-eluting stent implantation. EuroIntervention. 2014;9:1085-94.

46. Pinilla-Echeverri N, Mehta SR, Wang J, et al. Nonculprit lesion plaque morphology in patients with ST-segment-elevation myocardial infarction: results from the COMPLETE trial optical coherence tomography substudys. Circ Cardiovasc Interv. 2020;13:e008768.

47. Prati F, Romagnoli E, Gatto L, et al. Relationship between coronary plaque morphology of the left anterior descending artery and 12 months clinical outcome: the CLIMA study. Eur Heart J. 2020;41:383-91.

48. Xing L, Higuma T, Wang Z, et al. Clinical significance of lipidrich plaque detected by optical coherence tomography: a 4-year follow-up study. J Am Coll Cardiol. 2017;69:2502-13. 
49. Maehara A, Ben-Yehuda O, Ali Z, et al. Comparison of stent expansion guided by optical coherence tomography versus intravascular ultrasound: the ILUMIEN II study (observational study of optical coherence tomography [OCT] in patients undergoing fractional flow reserve [FFR] and percutaneous coronary intervention). JACC Cardiovasc Interv. 2015;8:1704-14.

50. Prati F, Romagnoli E, Burzotta F, et al. Clinical impact of OCT findings during PCI: the CLI-OPCI II study. JACC Cardiovasc Imaging. 2015;8:1297-305.

51. Erlinge D, Maehara A, Ben-Yehuda O, et al. Identification of vulnerable plaques and patients by intracoronary near-infrared spectroscopy and ultrasound (PROSPECT II): a prospective natural history study. Lancet. 2021;397:985-95.

52. Stone PH, Maehara A, Coskun AU, et al. Role of low endothelial shear stress and plaque characteristics in the prediction of nonculprit major adverse cardiac events: the PROSPECT study. JACC Cardiovasc Imaging. 2018;11:462-71.

53. Cheng JM, Garcia-Garcia HM, de Boer SP, et al. In vivo detection of high-risk coronary plaques by radiofrequency intravascular ultrasound and cardiovascular outcome: results of the ATHEROREMO-IVUS study. Eur Heart J. 2014;35:639-47.

54. Gao XF, Ge Z, Kong XQ, et al. 3-year outcomes of the ULTIMATE trial comparing intravascular ultrasound versus angiography-guided drug-eluting stent implantation. JACC Cardiovasc Interv. 2021;14:247-57.

55. Kennedy MW, Fabris E, Ijsselmuiden AJ, et al. Combined optical coherence tomography morphologic and fractional flow reserve hemodynamic assessment of non- culprit lesions to better predict adverse event outcomes in diabetes mellitus patients: COMBINE (OCT-FFR) prospective study. Rationale and design. Cardiovasc Diabetol. 2016;15:144.

56. Wijns W, Shite J, Jones MR, et al. Optical coherence tomography imaging during percutaneous coronary intervention impacts physician decision-making: ILUMIEN I study. Eur Heart J. 2015;36:3346-55.

57. Ali ZA, Maehara A, Généreux P, et al. Optical coherence tomography compared with intravascular ultrasound and with angiography to guide coronary stent implantation (ILUMIEN III: OPTIMIZE PCI):a randomised controlled trial. Lancet. 2016;388:2618-28.

58. Stone GW, Maehara A, Ali ZA, et al. Percutaneous coronary intervention for vulnerable coronary atherosclerotic plaque. J Am Coll Cardiol. 2020;76:2289-301.

59. Stone PH, Saito S, Takahashi S, et al. Prediction of progression of coronary artery disease and clinical outcomes using vascular profiling of endothelial shear stress and arterial plaque characteristics: the PREDICTION study. Circulation. 2012;126:172-81.

60. de la Torre Hernandez JM, Hernández Hernandez F, Alfonso F, et al. Prospective application of pre-defined intravascular ultrasound criteria for assessment of intermediate left main coronary artery lesions results from the multicenter LITRO study. J Am Coll Cardiol. 2011;58:351-8.

61. Thomsen C, Abdulla J. Characteristics of high-risk coronary plaques identified by computed tomographic angiography and associated prognosis: a systematic review and meta-analysis. Eur Heart J Cardiovasc Imaging. 2016;17:120-9.

62. Nørgaard BL, Leipsic J, Gaur S, et al. Diagnostic performance of noninvasive fractional flow reserve derived from coronary computed tomography angiography in suspected coronary artery disease: the NXT trial (analysis of coronary blood flow using CT angiography: next steps). J Am Coll Cardiol. 2014;63:1145-55.

63. Bom MJ, Schumacher SP, Driessen RS, et al. Non-invasive procedural planning using computed tomography-derived fractional flow reserve. Catheter Cardiovasc Interv. 2021;97:614-22.

64. Collet C, Sonck J, Leipsic J, et al. Implementing coronary computed tomography angiography in the catheterization laboratory. JACC Cardiovasc Imaging. 2021;14:1846-55.
65. Wyffels E, Bermpeis K, Mileva N et al. CT-guided roboticassisted revascularisation in multi-vessel coronary artery disease. https://www.pcronlinecom/Cases-resources-images/Cases/Readshare-cases/2021/CT-guided-Robotic-assisted-revascularisationmulti-vessel-coronary-artery-disease?auth=true\#comments_area. Accessed Sep 2021.

66. Reeh J, Therming CB, Heitmann M, et al. Prediction of obstructive coronary artery disease and prognosis in patients with suspected stable angina. Eur Heart J. 2019;40:1426-35.

67. Kunadian V, Chieffo A, Camici PG, et al. An EAPCI expert consensus document on ischaemia with non-obstructive coronary arteries in collaboration with European Society of Cardiology Working Group on Coronary Pathophysiology \& Microcirculation Endorsed by Coronary Vasomotor Disorders International Study Group. Eur Heart J. 2020;41:3504-20.

68. Jespersen L, Hvelplund A, Abildstrøm SZ, et al. Stable angina pectoris with no obstructive coronary artery disease is associated with increased risks of major adverse cardiovascular events. Eur Heart J. 2012;33:734-44.

69. Taqueti VR, Di Carli MF. Coronary microvascular disease pathogenic mechanisms and therapeutic options: JACC stateof-the-art review. J Am Coll Cardiol. 2018;72:2625-41.

70. Kodeboina M, Nagumo S, Munhoz D, et al. Simplified assessment of the index of microvascular resistance. J Interv Cardiol. 2021;2021:9971874.

71. Gallinoro E, Candreva A, Colaiori I et al. Thermodilutionderived volumetric resting coronary blood flow measurement in humans. EuroIntervention. 2021.

72. Candreva A, Gallinoro E, van't Veer M, et al. Basics of coronary thermodilution. JACC Cardiovasc Interv. 2021;14:595-605.

73. Mileva N, Nagumo S, Mizukami T et al. Prevalence of coronary microvascular disease and coronary vasospasm in patients with non-obstructive coronary artery disease: systematic review and meta-analysis. J Am Heart Assoc. 2021. (in press).

74. De Bruyne B, Pijls NHJ, Gallinoro E, et al. Microvascular resistance reserve for assessment of coronary microvascular function: JACC technology corner. J Am Coll Cardiol. 2021;78:1541-9.

75. Volpe M, Trimarco B, Battistoni A, Mancia G. Clinical management of coronary heart disease in hypertension: practical recommendations from the Italian Society of Hypertension (SIIA). High Blood Press Cardiovasc Prev. 2013;20:129-34.

76. Baigent C, Keech A, Kearney PM, et al. Efficacy and safety of cholesterol-lowering treatment: prospective meta-analysis of data from 90,056 participants in 14 randomised trials of statins. Lancet. 2005;366:1267-78.

77. Robinson JG, Wang S, Smith BJ, Jacobson TA. Meta-analysis of the relationship between non-high-density lipoprotein cholesterol reduction and coronary heart disease risk. J Am Coll Cardiol. 2009;53:316-22.

78. Sabatine MS, Giugliano RP, Keech AC, et al. Evolocumab and clinical outcomes in patients with cardiovascular disease. $\mathrm{N}$ Engl J Med. 2017;376:1713-22.

79. Schwartz GG, Steg PG, Szarek M, et al. Alirocumab and cardiovascular outcomes after acute coronary syndrome. N Engl J Med. 2018;379:2097-107.

80. Visseren FLJ, Mach F, Smulders YM, et al. 2021 ESC guidelines on cardiovascular disease prevention in clinical practice. Eur Heart J. 2021;42:3227-337.

81. Mach F, Baigent C, Catapano AL, et al. 2019 ESC/EAS guidelines for the management of dyslipidaemias: lipid modification to reduce cardiovascular risk. Eur Heart J. 2020;41:111-88.

82. Chhatriwalla AK, Nicholls SJ, Nissen SE. The ASTEROID trial: coronary plaque regression with high-dose statin therapy. Future Cardiol. 2006;2:651-4.

83. Crouse JR 3rd, Raichlen JS, Riley WA, et al. Effect of rosuvastatin on progression of carotid intima-media thickness in low-risk 
individuals with subclinical atherosclerosis: the METEOR trial. JAMA. 2007;297:1344-53.

84. Nicholls SJ, Puri R, Anderson T, et al. Effect of evolocumab on progression of coronary disease in statin-treated patients: the GLAGOV randomized clinical trial. JAMA. 2016;316:2373-84.

85. Williams B, Mancia G, Spiering W, et al. 2018 ESC/ESH guidelines for the management of arterial hypertension. Eur Heart J. 2018;39:3021-104.

86. Baigent C, Blackwell L, Collins R, et al. Aspirin in the primary and secondary prevention of vascular disease: collaborative meta-analysis of individual participant data from randomised trials. Lancet. 2009;373:1849-60.

87. Yusuf S, Zhao F, Mehta SR, Chrolavicius S, Tognoni G, Fox KK. Effects of clopidogrel in addition to aspirin in patients with acute coronary syndromes without ST-segment elevation. N Engl J Med. 2001;345:494-502.

88. Wiviott SD, Braunwald $\mathrm{E}, \mathrm{McCabe} \mathrm{CH}$, et al. Prasugrel versus clopidogrel in patients with acute coronary syndromes. N Engl J Med. 2007;357:2001-15.

89. Wallentin L, Becker RC, Budaj A, et al. Ticagrelor versus clopidogrel in patients with acute coronary syndromes. N Engl J Med. 2009;361:1045-57.

90. Mauri L, Kereiakes DJ, Yeh RW, et al. Twelve or 30 months of dual antiplatelet therapy after drug-eluting stents. N Engl J Med. 2014;371:2155-66.

91. Bonaca MP, Bhatt DL, Cohen M, et al. Long-term use of ticagrelor in patients with prior myocardial infarction. N Engl J Med. 2015;372:1791-800.
92. Bhatt DL, Steg PG, Mehta SR, et al. Ticagrelor in patients with diabetes and stable coronary artery disease with a history of previous percutaneous coronary intervention (THEMISPCI): a phase 3, placebo-controlled, randomised trial. Lancet. 2019;394:1169-80.

93. Furtado RHM, Nicolau JC, Magnani G, et al. Long-term ticagrelor for secondary prevention in patients with prior myocardial infarction and no history of coronary stenting: insights from PEGASUSTIMI 54. Eur Heart J. 2020;41:1625-32.

94. Oldgren J, Wallentin L, Alexander JH, et al. New oral anticoagulants in addition to single or dual antiplatelet therapy after an acute coronary syndrome: a systematic review and meta-analysis. Eur Heart J. 2013;34:1670-80.

95. Mega JL, Braunwald E, Wiviott SD, et al. Rivaroxaban in patients with a recent acute coronary syndrome. N Engl J Med. 2012;366:9-19.

96. Chiarito M, Cao D, Cannata F, et al. Direct oral anticoagulants in addition to antiplatelet therapy for secondary prevention after acute coronary syndromes: a systematic review and meta-analysis. JAMA Cardiol. 2018;3:234-41.

97. Eikelboom JW, Connolly SJ, Bosch J, et al. Rivaroxaban with or without aspirin in stable cardiovascular disease. N Engl J Med. 2017;377:1319-30.

98. Steffel J, Eikelboom JW, Anand SS, et al. The COMPASS trial: net clinical benefit of low-dose rivaroxaban plus aspirin as compared with aspirin in patients with chronic vascular disease. Circulation. 2020;142:40-8. 